\title{
Inovação tecnológica no trabalho final de curso no mestrado profissional
}

\section{Technological innovation in the course conclusion work in the professional master}

\section{Innovación tecnológica en el trabajo final de curso en la maestría profesional}

http://dx.doi.org/10.21713/2358-2332.2016.v13.970

Cleiton Fernando Barbosa Brito, mestrando em Produção Vegetal no Semiárido no Instituto Federal de Educação, Ciência e Tecnologia Baiano (IFBaiano), Guanambi, BA, Brasil. E-mail: cleiton.ibce@ hotmail.com.

Helder Henrique Neves Faria, mestrando em Produção Vegetal no Semiárido no Instituto Federal de Educação, Ciência e Tecnologia Baiano (IFBaiano), Guanambi, BA, Brasil. E-mail: helder.faria@ outlook.com.

Carlindo Santos Rodrigues, doutor em Zootecnia pela Universidade Federal de Viçosa (UFV), professor e pesquisador do Instituto Federal de Educação, Ciência e Tecnologia Baiano (IFBaiano), Salvador, BA, Brasil. E-mail: carlindo.rodrigues@ifbaiano.edu.br.

\section{Resumo}

A inovação tecnológica é um fator fundamental para a manutenção de atividades e para o crescimento e o desenvolvimento socioeconômico do país. Dessa forma, a integração entre inovação e mestrado profissional pode gerar potencialidades, pois há um esforço no sentido de afirmar sua identidade como categoria de curso de pós-graduação com estrutura de base inovadora. Alguns trabalhos vêm sendo publicados na tentativa de entender como a modalidade de mestrado profissional vem se constituindo, 
mas ainda sem tomarem como objeto de estudo a inovação tecnológica nos trabalhos finais do curso. Neste contexto, objetivou-se realizar, por meio de uma revisão de literatura, uma abordagem sobre inovação tecnológica como trabalho final de curso no mestrado profissional.

Palavras-chave: Mestrado Profissional. Lei de Inovação. NITs. Tipos de Inovação.

\section{Abstract}

Technological innovation is a key factor in maintenance activities and for the growth and socioeconomic development of the country. Thus, the integration of innovation and the professional master can generate potentialities because there is an effort to assert its identity as a category of graduate program with an innovative base structure. Some works have been published in an attempt to understand how the professional master mode is constituted, but these still do not take as the object of study the technological innovation in the concluding work of the course. In this context, this article aims to achieve, through a literature review, an approach to technological innovation as the course completion work in the professional master.

Keywords: Professional Master. Innovation Law. NITs. Types of Innovation.

\section{Resumen}

La innovación tecnológica es un factor clave para el mantenimiento de actividades y para el crecimiento y el desarrollo socioeconómico del país. Por lo tanto, la integración entre innovación y maestría profesional puede generar potencialidades porque hay un esfuerzo por afirmar su identidad como categoría de curso de postgrado con estructura de base innovadora. Algunos trabajos han sido publicados en un intento por entender cómo la modalidad de maestría profesional se constituye, pero aún sin tomar como objeto de estudio de la innovación tecnológica en los trabajos finales del curso. En este contexto, se pretende lograr, a través de una revisión de la literatura, un abordaje de la innovación tecnológica como trabajo final de curso en la maestría profesional.

Palabras clave: Maestría Profesional. Ley de Innovación. NITs. Tipos de Innovación. 


\section{INTRODUÇÃo}

A necessidade de aperfeiçoamento de técnicas e operações nas empresas, nos serviços e nos negócios é notória, tendo em vista a competitividade local, regional e global em tais setores. Entretanto, esse aperfeiçoamento só é atingido na medida em que há profissionais qualificados e envolvidos com o objetivo (BARBOZA; PASOTTO, 2014). Nesse cenário, o mestrado profissional (MP) pode ser uma estratégia para suprir a demanda por esse tipo de profissional.

O MP surgiu no Brasil, regulamentado pela Portaria Capes $n^{\circ}$ 80/1998, com o objetivo de qualificar um determinado público para diversos setores da sociedade (LATINI et al., 2011). O objetivo, de acordo com o Plano Nacional de Pós-Graduação (PNPG) 2011-2020, é o de atender às demandas sociais sem que se perca o viés científico da formação, a fim de capacitar profissionais que, mais do que consumidores, sejam produtores de conhecimento, seja para o mercado não acadêmico, seja para a pesquisa e docência universitárias (BARRETO; DOMINGUES, 2012; BRASIL, 2010).

O MP deve focar temas de interesse público, por meio da difusão, da produção e da aplicação do conhecimento, do método e da redação científicos na solução de problemas específicos do mundo do trabalho e do sistema produtivo de bens e serviços, em uma perspectiva de pesquisa aplicada direcionada à inovação de tecnologias, produtos e processos, no setor privado ou público, à procura de maior eficácia e eficiência das organizações, com o consequente aumento de sua produtividade (MAMEDE, 2015).

De acordo com a Portaria Normativa MEC $n^{\circ} 17$, de 28 de dezembro de 2009, a oferta de cursos com vistas à formação no mestrado profissional tem como ênfase os princípios de aplicabilidade técnica, de flexibilidade operacional e de organicidade do conhecimento técnico-científico, visando ao treinamento de pessoal, pela exposição dos alunos aos processos da utilização aplicada dos conhecimentos e ao exercício da inovação, a fim de valorizar a experiência profissional. 
A proposta de MP prevê a exigência de apresentação de trabalho final do curso. No entanto, diferentemente do que ocorre no mestrado acadêmico, o trabalho final poderá ser apresentado em diversos formatos, tais como dissertação, revisão sistemática e aprofundada de literatura, artigo, patente, registros de propriedade intelectual, projetos técnicos, publicações tecnológicas e desenvolvimento de aplicativos, de materiais didáticos e instrucionais, de produtos e de projetos de inovação tecnológica. Nesse sentido, entre os diferentes formatos de trabalho de conclusão de curso do mestrado profissional, seria importante que a inovação estivesse presente em todos.

De acordo com a Lei Federal n 10.973, de 2 de dezembro de 2004 - Lei de Inovação - capítulo I, art. $2^{\circ}$, inciso IV, inovação é a introdução de novidade ou o aperfeiçoamento no ambiente produtivo ou social que resulte em novos produtos, processos ou serviços. Segundo o Manual de Oslo (OECD, 2006), a inovação consiste na implementação de um bem ou serviço novo ou significativamente melhorado, bem como um processo, um método de marketing ou um novo método organizacional.

Para Czelusniak (2010), o conceito de inovação se refere à apropriação e/ou ao uso comercial/social de "novidades", descobertas, invenções e conhecimentos, ou, ainda, à introdução de aperfeiçoamentos nos bens e serviços utilizados pela sociedade. Contudo, inovação tecnológica é aquela que surge após o uso da tecnologia como meio para introduzir mudanças na organização, podendo ser classificada em dois tipos: de produto e de processo.

A inovação tecnológica compreende a implantação de um produto ou de um processo tecnologicamente novo ou com substanciais melhorias tecnológicas. Todavia, ela só é considerada implantada se tiver sido introduzida no mercado (inovação de produto) ou usada no processo de produção (inovação de processo).

De acordo com Fuck e Vilha (2012), a geração de inovação tecnológica pode ser caracterizada como um processo multifacetado que envolve a integração de várias funções da empresa e de atores externos (Figura 1). A empresa interage e combina seus conhecimentos internos com fontes externas de informação e de cooperação tecnológica, como clientes, 
fornecedores, universidades, concorrentes e institutos públicos e privados de pesquisa. Salienta-se que as inovações de natureza tecnológica têm a necessidade de estar, em grande medida, baseadas em conhecimento científico e técnico. Dessa forma, as grandes parceiras da empresa na busca por conhecimento são as universidades e, atualmente, também os institutos federais.

\section{Figura 1 - Processo de inovação tecnológica}

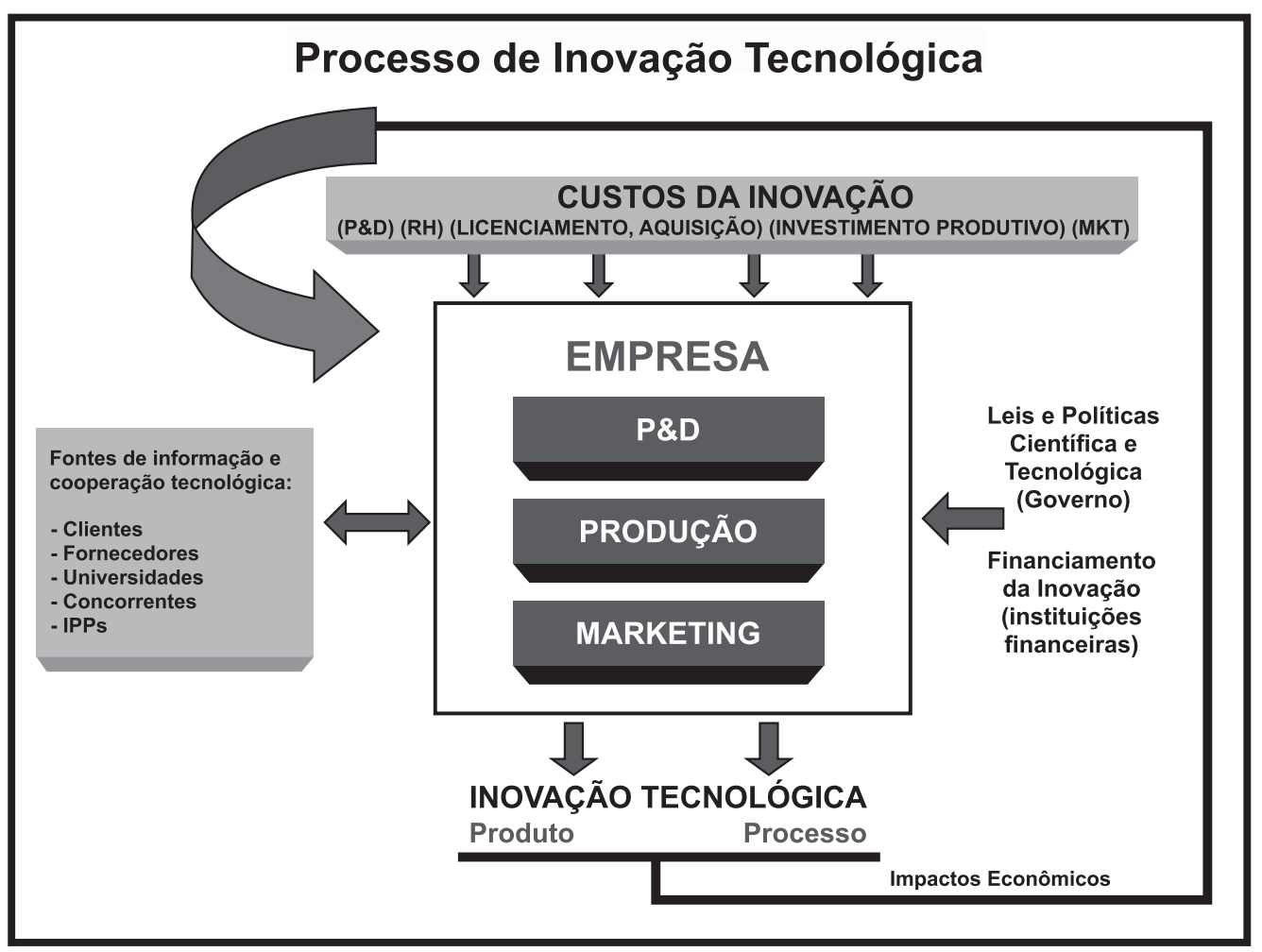

Fonte: OECD, 2006.

Em relação aos institutos federais, quanto aos modelos empresauniversidade-governo adotados, o que melhor se adapta à sua realidade é o Triângulo de Sábato, um modelo de política científica e tecnológica para orientar como e onde inovar. Esse modelo reconhece que, para existir uma estrutura científica e tecnológica produtiva, são necessários três elementos que devem interagir de forma permanente: a universidade/ instituto federal (que cria), a empresa (que aplica) e o governo (que estimula). Esses elementos representam um triângulo em que os vértices se relacionam entre si com o objetivo de gerar, incorporar e transformar demandas em um produto final, a inovação científica e tecnológica (PERUCCHI; MUELLER, 2016). 
O gerenciamento de inovação tecnológica busca a coordenação, a mobilização e a integração dos recursos e dos atores internos (direção da empresa, pesquisa e desenvolvimento, marketing, operações, recursos humanos e financeiros, novos negócios) com os atores externos à empresa (clientes, fornecedores, concorrentes, instituições de pesquisa e de fomento), para explorar oportunidades tecnológicas (FUCK; VILHA, 2012). Nesse contexto, o MP deve buscar parcerias com base no viés de integração de conhecimento que empresas buscam fora do seu ambiente de trabalho. No entanto, principalmente nos institutos federais, onde aumentou o número de MPs nos últimos anos, existe uma relação mais forte entre a instituição e o governo, sendo poucas as parcerias entre institutos federais e empresas na condução de pesquisas (PERUCCHI; MUELLER, 2016).

A inovação tecnológica pode ser classificada como radical ou incremental, com base no grau de novidade envolvido. A inovação radical consiste no desenvolvimento ou na comercialização de produtos totalmente novos a partir de resultados de pesquisa. Normalmente, a inovação radical pressupõe grandes investimentos em pesquisa, entretanto, como contrapartida, permite à empresa assumir um monopólio no mercado e lançar um produto sem concorrência imediata e direta (ROCHA NETO, 2003).

Já a inovação incremental consiste na melhora ou no aperfeiçoamento de produtos, processos e serviços existentes no mercado. Assim, a partir dos conhecimentos já existentes na organização e da identificação de novos problemas, busca-se maior eficiência no uso de matéria-prima ou melhora nos produtos finais, com baixo custo. Normalmente, esse tipo de inovação requer pouco esforço em pesquisa, pois está concentrado somente na fase de desenvolvimento, sendo decorrente do aproveitamento de esforço em pesquisa de outro inovador (ROCHA NETO, 2003). A importância das inovações incrementais reside justamente no fato de que esses tipos são mais fáceis de serem gerados e, nesse sentido, preenchem continuamente o processo de mudança nos mercados (VILHA, 2009).

Existe outro tipo de inovação tecnológica chamada de disruptiva. Esse tipo de tecnologia é usado por empresas inovadoras que inserem, 
nas camadas mais baixas do mercado, as tecnologias de ruptura, ou seja, mais baratas, mais simples, com produtos ou serviços mais convenientes. É importante destacar que estratégias de inovação tecnológicas pautadas apenas no contexto incremental podem não ser efetivas em um contexto disruptivo, podendo levar tecnologias incrementais ao fracasso (CHRISTENSEN, 2001).

Em todas as definições, fica subentendido que a inovação necessita de vários tipos de tecnologia e de conhecimento oriundos de diferentes fontes, incluindo indústria, empresas, laboratórios, institutos de pesquisa e desenvolvimento, academia e consumidores (AMADEl; TORKOMIAN, 2009). Além disso, pode-se perceber que a inovação é um fator fundamental para a manutenção de atividades e para o crescimento e o desenvolvimento socioeconômico do país. Assim, a integração entre inovação e MP pode gerar potencialidades, pois há um esforço no sentido de afirmar sua identidade como categoria de curso de pós-graduação com estrutura de base inovadora, na medida em que contribui para o processo de inovação, haja vista seus entrelaces com os movimentos extra-acadêmicos (NASCIMENTO; PIÑEIRO; RAMOS, 2013).

Em uma visão interna à universidade, de modo geral, percebe-se que apenas alguns departamentos ou grupos de pesquisadores isolados mantêm relações com o empresariado público ou privado. Isso ocorre pelo fato de a cultura de inovação ainda não ter se popularizado no ambiente acadêmico, havendo também pesquisadores que não veem com bons olhos essas relações com o meio externo, talvez por um senso de preservação da identidade acadêmica tradicional (NASCIMENTO; PIÑEIRO; RAMOS, 2013).

As universidades marcaram a trajetória de inovação de muitos países, entre eles pode-se destacar os Estados Unidos, que, após a $2^{a}$ Guerra Mundial, apoiaram as pesquisas básicas nas instituições norteamericanas e, com isso, conseguiram recuperar sua economia e emergir como potência mundial por meio do estreitamento das relações das universidades com a indústria. A partir de então, as universidades passaram a ser consideradas elementos estratégicos para o desenvolvimento econômico e tecnológico do país (AMADEl; TORKOMIAN, 2009). 
Como descrito anteriormente, a inovação em um país pode trazer diversas vantagens, e a aproximação da academia com o meio produtivo caracteriza-se como estratégia fundamental para esse processo. Dessa forma, com base na sua proposta de gerar pesquisas voltadas para uma determinada área do saber com a articulação entre instituição de ensino, governo e iniciativa privada, o MP pode ser um aliado. Para isso, deve ocorrer um esforço de toda a comunidade acadêmica no sentido de reconhecer a importância de adentrar efetivamente na era da inovação e de renovar processos defasados que interferem no sucesso dos empreendimentos.

Atualmente, é escassa a literatura que discute a interação empresa-instituição de ensino. Entre os poucos estudos disponíveis, Vilela, Callegaro e Gama (2013) apresentam experiência pioneira realizada pelo Projeto Inovação Tecnológica para Defesa Agropecuária (Inova Defesa - UFV, CTagro/MCTI e CNPq) - na implantação de cursos de mestrado profissional em Defesa Agropecuária em universidades brasileiras, no período 2008-2012. Para realização dessa experiência, inicialmente, foi diagnosticado um dos importantes gargalos do sistema brasileiro de defesa agropecuária: o distanciamento das universidades e dos centros de pesquisa dos órgãos de defesa agropecuária do Ministério da Agricultura, Pecuária e Abastecimento (Mapa), das secretarias de estado de Agricultura e das agências que trabalham na área da defesa sanitária. Em virtude dessa distância, os profissionais graduados em Agronomia e Medicina Veterinária carecem, na maioria das vezes, do perfil requisitado pelas agências de defesa agropecuária para o exercício profissional na área. Portanto, o projeto contribuiu para a melhoria do setor, com a criação de mestrados profissionais para a capacitação de recursos humanos em defesa agropecuária, aproximando, dessa forma, a universidade e os órgãos executores da fiscalização sanitária.

Esse exemplo mostra de forma clara que a finalidade do MP é gerar conhecimento para atender às demandas sociais, organizacionais ou profissionais. A criação do MP em Defesa Agropecuária pode ser considerada uma inovação, uma vez que vem a atender um gargalo importante do setor. Imagina-se que os trabalhos finais desse mestrado sejam inovações para a área de defesa agropecuária. 
Apesar de o conhecimento sobre a importância da relação instituição de ensino-empresa, os mecanismos adotados podem não estar contribuindo para o processo de inovação oriundo dos trabalhos finais de curso. Segundo Lotufo (2009), o aspecto principal da contribuição da universidade para o desenvolvimento da inovação no Brasil é a formação dos alunos, que são estimulados ao empreendedorismo, por meio do apoio à criação de empresas voltadas para o autocrescimento. Consequentemente, aumentam as chances de incorporação dos resultados das pesquisas e das criações universitárias (trabalhos finais) em benefício da sociedade.

De acordo com Latini et al. (2011), alguns estudos vêm sendo publicados na tentativa de entender como a modalidade de MP vem se constituindo, mas ainda sem tomarem como objeto de análise os trabalhos finais de curso que vêm sendo produzidos. Nesse contexto, objetivou-se realizar, por meio de revisão de literatura, uma abordagem sobre inovação tecnológica como trabalho final de curso no mestrado profissional. Foram buscados artigos científicos disponíveis na biblioteca eletrônica Scientific Electronic Library Online (SciELO) e no Portal de Periódicos da Capes, utilizando-se os descritores "inovação tecnológica", "trabalho de conclusão de curso" e "mestrado profissional". Para a seleção dos artigos da pesquisa, foram identificados os que apresentavam informações relevantes sobre o tema, tais como conceitos e modelos de MP de diferentes instituições de ensino superior.

\section{INOVAÇÃO TECNOLÓGICA NO TRABALHO FINAL DE CURSO}

Apesar de a Lei da Inovação (Lei n 10.973, de 2 de dezembro de 2004), que regulamenta a produção e a transferência da tecnologia gerada na universidade para o ambiente produtivo, além de propiciar maior mobilidade para os pesquisadores, que podem empreender pesquisas no setor privado, ainda não se observa avanço significativo no processo de inovação tecnológica nas instituições de ensino. A inovação tecnológica no Brasil continua com resultados parecidos com aqueles observados anteriormente à promulgação da lei, sendo que as pesquisas realizadas nacionalmente estão gerando poucos processos de inovação (CZELUSNIAK, 2010). 
Outro fator importante que tem contribuído negativamente para os processos de inovação é o aparato burocrático, principalmente, jurídico e institucional, hoje existente nas instituições de ensino e de pesquisa e, que, muitas vezes, onera o processo de parcerias, aumentando os custos de transação e promovendo atrasos na implementação de pesquisas e projetos conjuntos.

Muitas vezes, na universidade, mesmo em parceria com empresas, o objetivo do trabalho final do curso é, na maior parte, voltado para a área acadêmica, na forma de dissertações e artigos científicos. Assim, um trabalho que poderia ganhar um caráter inovador acaba por ficar restrito a um público pequeno da área acadêmica. Por isso, há muita expectativa no sentido de que a modalidade de MP venha a suprir essa carência de trabalhos finais com aspecto inovador, devido à diferença de formas como eles podem ser apresentados.

Os discentes de um MP estão envolvidos com atividades de pesquisa voltadas, principalmente, para a elaboração de seus trabalhos finais de curso. Dessa forma, os trabalhos finais devem estar voltados às pesquisas tecnológicas que visam à solução de um problema com a aplicação de ferramentas que possam tornar-se produtos, serviços ou processos no ambiente produtivo. Nesse sentido, se esses projetos apresentam grande tendência de se tornarem produtos inovadores, podem acabar sendo financiados por empresas que têm interesse naquela tecnologia ou por órgãos de fomento que acreditam na potencialidade do projeto, entre outros.

A adoção de estratégias e práticas inovadoras nas empresas está estreitamente associada à busca de diferenciações capazes de gerar produtos e serviços para o mercado que tragam vantagens competitivas sustentáveis em relação a seus competidores (VILHA, 2009). Dessa forma, as instituições de ensino devem buscar parcerias com empresas para a realização de suas pesquisas dentro da instituição. Com isso, o trabalho final poderá ter um caráter inovador e resultar em produto que atenda à determinada demanda.

A inovação nos trabalhos finais de curso do MP poderá trazer bons resultados para a elevação dos números de processos de inovação 
no Brasil. A forma como será realizada a gestão das articulações entre os atores e, também, dos mecanismos de propriedade intelectual pelas instituições de pesquisa em relação aos trabalhos finais de curso e seus parceiros e colaboradores será essencial para o sucesso dos projetos e sua consequente chegada ao mercado (inovação).

As ações das instituições de ensino devem ser implementadas para criar um cenário propício às inovações tecnológicas oriundas dos trabalhos finais de curso. Entre as ações que poderiam ser tomadas, pode-se destacar a de a instituição não induzir o aluno de MP a conduzir o seu trabalho final nos moldes de um trabalho de mestrado acadêmico, ou seja, não o levar a produzir apenas uma dissertação para, posteriormente, publicá-la na forma de artigo científico. Afinal, dessa maneira, o estudante pode perder o diferencial que tem na maioria das vezes: o conhecimento prático, o conhecimento dos gargalos do mercado de trabalho e da área e/ou região na qual atua.

Outra ação importante que a instituição pode realizar é a criação do Núcleo de Inovação Tecnológica (NIT) - definido pela Lei n 10.973/2004 como "núcleo ou órgão constituído por uma ou mais Instituição de Ciência e Tecnologia com a finalidade de gerir sua política de inovação"-, com o viés de incentivar a inovação tecnológica nos trabalhos finais de curso. Essa ação é importante porque, nas instituições de ensino superior, o NIT é responsável por gerir a política de inovação, além de formar parcerias com empresas e organizações de direito privado (MALVEZZI; ZAMBALDE; REZENDE, 2014).

De acordo com Czelusniak (2010), alguns pontos da Lei de Inovação, que define como a instituição de ensino irá conduzir a proteção da propriedade intelectual, podem trazer consequências na maneira de criar e desenvolver os projetos de conclusão do curso. Isso porque, as medidas adotadas podem implicar a modificação da relação entre instituição de ensino, estudantes, professores e empresas. Assim, o quadro normativo estabelecido pela instituição em seu regulamento interno pode influenciar diretamente as posturas dos agentes envolvidos, podendo, por exemplo, induzir atitudes mais defensivas nos trabalhos finais de curso, diminuindo a interação instituição de ensino-empresa proposta pela lei. 
Tal contexto já foi evidenciado em estudo realizado por Dergint e Amaro (2007), que levantaram algumas questões referentes à introdução das normas de apropriação de propriedade intelectual da Lei de Inovação para a unidade da Universidade Tecnológica Federal do Paraná (UTFPR), em Curitiba. $\mathrm{O}$ trabalho procurou identificar a impressão dos alunos daquela instituição quanto à apropriação da propriedade intelectual pela instituição científica e tecnológica (ICT) sobre os trabalhos finais. Na pesquisa realizada, a maioria dos alunos considerou seus trabalhos finais como projetos de negócio próprio para possível comercialização no mercado. Os alunos tinham a convicção de que os trabalhos que realizavam eram de sua propriedade e, assim, demonstraram o receio de que a introdução das normas da Lei de Inovação na instituição levasse à apropriação pela universidade, restando-Ihes uma pequena parcela dos resultados advindos da proteção. Nesse sentido, segundo os estudantes, essas políticas seriam um desestímulo à inovação tecnológica, na medida em que não mais desenvolveriam projetos de seu interesse na universidade. Dessa forma, passariam a desenvolver projetos potencialmente menos inovadores, somente com o objetivo de cumprir o curriculum proposto pelo curso.

Os NITs podem ser importantes na implementação de políticas de inovação tecnológica nas instituições, tanto no auxílio à difusão da cultura da propriedade industrial ou intelectual como na viabilização da relação universidade-ambiente produtivo. Um bom exemplo a ser seguido pelos MPs é o de como a UTFPR lida com a inovação tecnológica nos trabalhos finais. O processo do trabalho final se inicia pela concepção da ideia do produto, verificando-se sua necessidade no mercado, por meio de análise mercadológica. Os discentes podem escolher livremente sua equipe, entretanto, para o cumprimento das atividades, eles são incentivados a trabalhar em grupo, tanto pela complexidade dos projetos quanto pelo objetivo traçado para o trabalho final de estimular a capacidade relacional. Assim, os docentes aconselham que o trabalho final seja realizado em equipe de três a quatro discentes, que podem ser colegas de turma de outros cursos ou mesmo de outras instituições. Os estudantes têm orientações sobre inovação tecnológica, gestão de projetos tecnológicos, empreendedorismo, mercado de trabalho, cenários, globalização e mundialização, e fontes de financiamento de projetos. Esses conteúdos específicos visam propiciar aos alunos o desenvolvimento de seus projetos dentro de um contexto inovador. 
Em decorrência da possibilidade de os trabalhos finais dos estudantes da UTFPR se tornarem inovação, os docentes das disciplinas de trabalho final de curso notaram a tentativa, por parte dos alunos, de empreender seus projetos no ambiente produtivo, ou seja, a chance de esses discentes desenvolverem um produto com algum tipo de inovação tecnológica é muito grande.

Segundo Velho (2007), a formação de pós-graduação no Brasil conseguiu construir um sistema de avaliação com critérios bem definidos e constantemente aperfeiçoados. Graças a esse sistema, é possivel saber a qualidade dos cursos, vários deles considerados em âmbito internacional. Entretanto, essa qualidade é definida unicamente com base nos valores internos à ciência, não havendo, entre os critérios adotados, nenhum que estimule a interação dos pesquisadores e dos alunos com o meio externo à universidade. Em consequência, os egressos da pós-graduação são preparados, geralmente, para desempenhar atividades acadêmicas e percebem, quando encontram trabalho em outros contextos institucionais, que a formação que tiveram não os preparou bem para aquela função. $A$ autora afirma que a percepção dos pós-graduandos que se dirigem para empregos fora da academia é a de que não estão totalmente preparados para as tarefas que desempenharão. Eles sentem falta especificamente de habilidades e competências relacionais, interativas e de negociação, que a dinâmica de inovação requer - e este é outro ponto para o qual os MPs devem atentar, buscando promover a formação dessas habilidades e competências nos pós-graduandos.

Boullosa (2011) afirma que, no processo de aprendizagem de cursos com formação profissional, o desenho ainda está sendo amadurecido, pois, muitas vezes, aproxima-se excessivamente daquele tradicional de uma graduação científica. Dessa forma, um dos caminhos plausíveis para o amadurecimento e a consolidação da inovação tecnológica na educação superior pode ser encontrado na ancoragem do ensino profissionalizante à realidade "socioprática" do campo de atuação do discente, o que orientaria o seu problema de pesquisa para esta mesma realidade, de modo que ela fosse abordada no trabalho final de curso.

A preocupação quanto à natureza do trabalho final no eixo tecnológico ou profissionalizante do ensino superior tem se mostrado 
consistente, sobretudo quando concerne aos desafios e potencialidades desse tipo de trabalho nos mestrados profissionais. Há uma forte tendência de padronização dos trabalhos finais dos cursos de todas as áreas, conduzindo-os a um modelo único de qualidade. Apesar de os critérios de avaliação serem múltiplos e variados, sem dúvida, conferese maior peso às publicações científicas oriundas dos professores e estudantes dos cursos. Com certeza, publicar é um indicador-chave de desempenho do sistema de pesquisa.

Nesse contexto, os gestores de MP devem ter cuidado na escolha dos critérios relativos aos trabalhos finais de curso dos estudantes, para não acabarem valorizando, sobretudo, as publicações como produto final, pois, quando se busca estimular a colaboração entre os que trabalham nas instituições de ensino e os demais segmentos da sociedade (como prioriza o MP), é necessário valorizar produtos resultantes dessas interações, e nem sempre eles são publicações.

Por outro lado, a qualidade dos cursos é avaliada de maneira sistemática (inclusive o MP), sinalizando aqueles que têm "excelência" e negando funcionamento para os "despreparados" para a tarefa de formação. No entanto, a qualidade é definida por critérios limitados, exclusivamente internos ao sistema social da ciência, ou seja, por meio de publicações, sem incentivos de recompensa para atividades alternativas.

Em relação aos diferentes formatos de trabalhos finais possíveis no MP, se, por um lado, podem trazer benefícios para a inovação tecnológica, por outro, uma instituição de ensino que deseja oferecer à comunidade um mestrado profissionalizante, em qualquer área de ensino, não encontrará indicações concretas sobre o trabalho final, exceto no que concerne a sua obrigatoriedade. Ao aceitar a obrigatoriedade, a instituição poderá, portanto, desenvolver qualquer formato para seu trabalho final, com ou sem prejuízo da qualidade do curso que deseja oferecer. Nesse sentido, as modalidades como patentes, registros de propriedade intelectual e novos produtos podem vir a trazer maiores benefícios à inovação tecnológica nos MPs.

Boullosa (2011) avaliou a aprendizagem no eixo tecnológico de formação em gestão social e apresentou um novo formato de trabalho final 
chamado de Multidisco. A proposta visa articular três diferentes tipologias de trabalho final com um conjunto de eixos de pesquisa construídos a partir das principais temáticas trabalhadas em seu curso de referência. O formato de disco foi adotado para propiciar ludicidade ao processo de construção e desenvolvimento do trabalho final e, ao mesmo tempo, para que o aluno se sinta mais seguro, trocando experiências com os colegas na construção do seu objeto de pesquisa dentro do eixo tecnológico de ensino. As três tipologias seriam: avaliação e monitoramento, intervenção e proposta de intervenção diante de determinado problema identificado pelo discente. Para a autora, o novo desafio que se coloca é a utilização do multidisco para orientar o desenvolvimento do trabalho final de pós-graduação dentro do mesmo eixo tecnológico de ensino. Haveria a integração dos dois níveis de ensino, o que potencializaria ancoragens verticais de saberes, com suas trocas e produção de conhecimento transdisciplinar entre comunidades de pesquisa profissional-tecnológica que integrem alunos de graduação tecnológica, especialização e mestrado profissional, dialogando em um único multidisco. Em relação a essa metodologia, sua utilização parece coerente, pois a maioria dos cursos de MP surgem em instituições que já têm conhecimento em áreas de ensino tecnológico e de graduação.

Para Nascimento, Piñeiro e Ramos (2013), o momento atual impõe uma revisão de conceitos, uma vez que as transformações em âmbito global, o avanço vertiginoso das tecnologias e as exigências de um mercado empresarial e industrial competitivo tencionam as relações da universidade com os atores externos e despertam nos profissionais o interesse por uma especialização diferenciada e múltipla e por um conhecimento mais aplicável, que se distancia do modelo acadêmico tradicional. Dessa forma, o MP seria essa especialização diferenciada e múltipla, e seu produto final (trabalho final) permitiria que os profissionais/pesquisadores gerassem um conhecimento mais aplicável.

Os MPs vêm para demonstrar que é possível inovar a partir da consistência entre o intelecto e a ação, revelando que esses fatores, quando integrados, suscitam mudanças e efeitos muito acentuados, imergindo, inclusive no campo da produção científica acadêmica, mas também na geração de processos caracterizados pelo seu cunho inovador. É preciso salientar a importância dos profissionais/pesquisadores 
formados nos MPs como sujeitos multiplicadores do fazer com cunho inovador (NASCIMENTO; PIÑEIRO; RAMOS, 2013).

\section{CONSIDERAÇÕES FINAIS}

Com base no que foi descrito sobre o MP, deve-se considerar que o trabalho final do curso pode deixar um legado inovador para a sociedade, seja na forma de um produto seja na de um processo. As características peculiares dessa modalidade de ensino fazem com que haja uma interação entre empresa-academia, o que "teoricamente" pode gerar um produto inovador realmente oriundo de uma demanda da sociedade, em âmbito local, regional ou nacional.

A inovação tecnológica tem sido considerada cada vez mais um importante instrumento de crescimento da produtividade das instituições e de impulso para o desenvolvimento econômico sustentável local e regional, e o trabalho final dos MPs deve ser orientado para atender a esse tipo de exigência da sociedade.

Ressalta-se que as instituições de ensino têm importante e essencial papel na geração desse produto inovador, desde a seleção dos docentes que irão participar do programa, até os critérios de ingresso dos discentes. As instituições têm de estimular o discente a buscar o ponto "estrangulador", ou seja, os principais problemas da realidade em que vive (no trabalho, na região, nos serviços...) e abordar essa questão em seu trabalho final do curso. Seguindo este modelo, possivelmente, há grande chance de que o produto gerado por meio desse trabalho seja uma "inovação tecnológica".

As instituições de ensino ou seus respectivos NITs devem trabalhar inicialmente os conceitos e as modalidades de inovação tecnológica (radical, incremental e disruptiva). 0 estudante tem de ter esse conceito de forma clara para não ficar com o pensamento restrito no que se refere à inovação.

Os MPs devem estimular em seus trabalhos finais o processo de inovação tecnológica, que não ocorre em espaços preestabelecidos, 
tampouco em áreas definidas, mas, sim, na maioria das vezes, em lugares inesperados, a partir de estratégias simples e oriundas da necessidade e da busca de soluções de problemas cotidianos.

\section{Referências}

AMADEI, J. R. P.; TORKOMIAN, A. L. V. As patentes nas universidades: análise dos depósitos das universidades públicas paulistas. Revista Ciência da Informação, Brasília, v. 38, n. 2, p. 9-18, 2009.

BOULLOSA, R. F. Aprendizagem no eixo tecnológico de formação em gestão social: apresentando o Multidisco. Revista Eletrônica da Residência Social do CIAGS/UFBA, Salvador, v. 2, n. 2, p. 211-225, 2011.

BARBOZA, M.; PASOTTO, L. H. P. O Mestrado Profissional em Inovação Tecnológica da UFTM: evoluções e tendências. Revista Brasileira de Ciência, Tecnologia e Inovação (RBCTI), v. 1, n. 1, p. 57-61, 2014.

BRASIL. Ministério da Educação. V Plano Nacional de Pós-Graduação - PNPG 2011-2020. Brasília, DF: Capes, 2010. Disponível em: <http:// www.capes.gov.br/component/content/article?id=4439>. Acesso em: 30 set. 2015.

BARRETO, F. C. S.; DOMINGUES, I. O PNPG 2011-2020: os desafios do país e o sistema nacional de pós-graduação. Educação em Revista, v. 28, n. 3, p. 17-53, 2012.

CHRISTENSEN, C. M. 0 dilema da inovação - Quando novas tecnologias levam empresas ao fracasso. Tradução: Edna Veiga. São Paulo: Makron Books, 2001.

\section{CZELUSNIAK, V. A. Trabalho de Conclusão de Curso e Inovação Tecnológica} em Instituição de Ciência e Tecnologia: aspectos jurídicos e fáticos. 2010. 165 f. Dissertação (Mestrado em Tecnologia) - Programa de PósGraduação em Tecnologia, Universidade Tecnológica Federal do Paraná, Curitiba, 2010. 
DERGINT, D. E. A.; AMARO, V. Propriedade industrial e projetos de graduação da engenharia industrial ênfase eletrônica e telecomunicações da UTFPR. In: CONGRESSO BRASILEIRO DE EDUCAÇÃO EM ENGENHARIA / COBENGE, 35., 2007, Curitiba, PR. Anais... Brasília/DF: ABENGE - Associação Brasileira de Ensino de Engenharia, 2007. v. 1, p. 3C02 - 1- 3CO2 - 14.

FUCK, M. P.; VILHA, A. M. Inovação Tecnológica: da definição à ação. Revista Contemporâneos, v. 2, n. 9, 2012.

LATINI, R. M.; OLIVEIRA, L. R.; ANJOS, M. B.; CARVALHO, R. H. S. B. F. Análise dos produtos de um mestrado profissional da área de ensino de ciências e matemática. Ensino, Saúde e Ambiente, v. 4, n. 2, p. 45-57, 2011.

LOTUFO, R. A. A institucionalização de núcleos de inovação tecnológica e a experiência da Inova Unicamp. In: SANTOS, M. E. R.; TOLEDO, P. T. M.; LOTUFO, R. A. Transferência de tecnologia: estratégias para a estruturação e gestão de núcleos de inovação tecnológica. Campinas: Komedi, 2009.

MALVEZZI, F. A.; ZAMBALDE, A. L.; REZENDE, D. C. Marketing de patentes à inovação: um estudo multicaso em universidades brasileiras. Revista Brasileira de Marketing, v. 13, n. 5, p. 109-123, 2014.

MAMEDE, W. O mestrado profissional brasileiro e o Mestrado em Saúde Pública Europeia: objetivos semelhantes por caminhos diferentes. Revista Brasileira de Pós-Graduação, Brasília, v. 12, n. 27, p. 147-169, 2015.

NASCIMENTO, F. S.; PIÑEIRO, M. G. R.; RAMOS, I. S. Inovação e pósgraduação: um estudo específico sobre o primeiro mestrado profissional em Educação na Bahia. Revista Brasileira de Pós-Graduação, Brasilia, v. 10, n. 20, p. 369 - 390, 2013.

OECD - Organization for Economic Co-operationand Development. Manual de Oslo - Diretrizes para coleta e interpretação de dados sobre inovação. OECD - tradução FINEP. Brasília: FINEP, 2006.

PERUCCHI, V.; MUELLER, S. P. M. Produção de conhecimento científico e tecnológico nos Institutos Federais de Educação, Ciência e Tecnologia: uma 
investigação sobre a sua natureza e aplicação. Perspectivas em Ciência da Informação, v. 21, n. 1, p.134-151, 2016.

ROCHA NETO, I. Gestão de organizações - Inovação, ciência e tecnologia. São Paulo: Atlas, 2003.

VELHO, L. O papel da formação de pesquisadores no sistema de inovação.

Ciência e Cultura, São Paulo, SP, v. 59, n. 4, 2007.

VILELA, E. F.; CALLEGARO, G. M.; GAMA, S. K. I. Mestrado profissional em Defesa Agropecuária: criação, implementação e resultados preliminares. RBPG, Brasília, v. 10, n. 22, p. 1009-1034, 2013.

VILHA, A. M. Gestão da Inovação na Indústria Brasileira de Higiene Pessoal, Perfumaria e Cosméticos: uma análise sob a perspectiva do desenvolvimento sustentável. 2009. 123 f. Tese (Doutorado em Política Científica e Tecnológica) -Departamento de Política Científica e Tecnológica, Instituto de Geociências da UNICAMP, Campinas, 2009.

Recebido em 17/04/2016 Aprovado em 22/07/2016 